\title{
Slow Progress in Preparing for Radiological and Nuclear Emergencies
}

Richard J. Hatchett, MD

$\mathrm{T}$ The articles by Dainiak et $\mathrm{al}^{1,2}$ and survey report by Latshaw et $\mathrm{al}^{3}$ that appear in this issue of Disaster Medicine and Public Health Preparedness address the state of US preparedness for radiological and nuclear emergencies and should prompt deliberation about what can be done to improve it. Radiological and nuclear emergencies occur infrequently but have been associated with both immediate and long-term health consequences and psychological distress in affected populations. ${ }^{4-7}$ These well-documented experiences notwithstanding, the rarity with which such emergencies occur has made it difficult to muster resources to prepare for their medical and public health consequences.

That difficulty has eased somewhat because of heightened concerns in the post-September 11, 2001, era about the potential acquisition of radiological or nuclear materials by terrorist groups. As Latshaw and colleagues note, the Centers for Disease Control and Prevention (CDC) has expanded its radionuclide bioassay testing capability and list of priority radioisotopes for which it is developing assays. Food and Drug Adminstrationapproved medical countermeasures (calcium and zinc diethylenetriaminepentaacetate, potassium iodide, and Prussian blue) and granulocyte colony-stimulating factor have been added to the Strategic National Stockpile, and since 2005, the Department of Health and Human Services has steadily increased investment in the development of improved therapeutics and diagnostics for radiation injury. In 2008, at the request of the Department of Homeland Security, the Institute of Medicine conducted a 2-part workshop to evaluate medical preparedness to respond to a nuclear detonation, and in June 2010, the White House released a revised edition of its Planning Guidance for Response to a Nuclear Detonation to support the planning efforts of state and local emergency managers. ${ }^{8,9}$ The report of the Institute of Medicine workshop described the response assets that the US government could bring to bear in the event of a detonation of an improvised nuclear device or other radiation emergency and the considerable gaps in preparedness that remain.

The 2 articles presented by Dainiak and colleagues on the management of acute radiation syndrome (ARS) represent an important benchmark in our efforts to improve the medical management of radiation casualties and to apply the standards of evidence-based medicine to current recommendations. The articles rose out of the results of a meeting of a panel of experts at the headquarters of the World Health Organization in Geneva, Switzerland, in March 2009. The World Health Organization convened this group of experts with the goal of establishing a "harmonized approach to the medical management of radiation exposure" and asked them to apply a standardized tool for grading the quality of evidence and strength of their consensus recommendations. ${ }^{10}$ The sporadic nature of radiation accidents, lack of randomized clinical trials, and incomplete or insufficient documentation of therapy in many published case reports made it all but impossible to apply the analytical tool (the Grading of Recommendations Assessment Development and Evaluation instrument) to the assessment of therapy of radiationinduced injury in organs other than the bone marrow, and even in the case of radiation-induced injury to the marrow (hematopoietic ARS), the human studies evaluated were observational in nature and deemed to be of low to moderate quality. Nevertheless, the panel of experts was able to make strong recommendations in support of the following:

- The administration of cytokines (granulocyte colonystimulating factor or granulocyte macrophage colonystimulating factor) to people with exposures $\geq 2$ Gy or when prolonged neutropenia is anticipated

- The prophylactic administration of $5-\mathrm{HT}_{3}$ receptor antagonists to prevent nausea and vomiting when the suspected exposure exceeds $2 \mathrm{~Gy}$

- The use of topical steroids, antibiotics, and antihistamines for radiation burns, ulcers, or blisters

- Excision and grafting of radiation ulcers or necrosis with intractable pain

- Administration of electrolyte replacement therapy and sedatives to individuals with significant burns, hypovolemia, and/or shock

- The provision of supportive care to individuals with the uniformly lethal neurovascular syndrome

The panel of experts was further able to make a strong recommendation against the use of systemic steroids in the absence of a specific indication and weak recommendations in support of a number of empirical interventions (including stem cell transplant) for which the accumulated evidence base in this setting is weak.

I suspect that few readers will be surprised by these recommendations, which scarcely deviate from prudent supportive care. The significance of the above-mentioned articles lies not in what they recommend but in the conclusions the authors reach about our knowledge of ARS and the state of our ability to manage it. We have, by the expert panel's account, a long, long way to go. 
The US government has undertaken substantive efforts to rectify these deficiencies. In 2005, the National Institute of Allergy and Infectious Diseases established a radiation countermeasures program, awarding grants and contracts to promote research on radiation-induced normal tissue injury and creating 8 academic centers for medical countermeasures against radiation focused on the development of improved therapeutics and diagnostics. In 2008, the Department of Health and Human Services's Biomedical Advanced Research and Development Authority awarded its first contracts for the advanced development of medical countermeasures against hematopoietic ARS, and the authority subsequently has awarded contracts to support the development of point-of-care and high-throughput radiation diagnostics, as well as therapeutics for gastrointestinal ARS and radiation-induced lung and skin injury. The road to Food and Drug Administration approval is fraught with peril, of course, but we can be cautiously optimistic that improved radiation countermeasures and diagnostics are on the way.

In a similar vein, the survey results reported by Latshaw and colleagues document other serious gaps in our radiological preparedness. In 2009 and again in 2011, the Association of Public Health Laboratories distributed surveys (the first as part of an all-hazards survey) to state public health laboratories that assessed their radiation readiness. These surveys achieved high response rates ( $98 \%$ and $76 \%$, respectively), so the results must be taken seriously. ${ }^{3}$ The data, unfortunately, are discouraging.

Only 17 (33\%) of 51 respondents to the 2009 survey reported any ability to measure radionuclides in clinical specimens, and $3(6 \%)$ of these indicated that a state agency or department other than the public health laboratory was responsible for testing. The 2011 Radiation Capability Survey solicited responses from environmental, agricultural, and public health laboratories in all 50 states, the District of Columbia, and Puerto Rico and reached similar conclusions. ${ }^{3}$ Just $26 \%$ of respondents reported the capability to test urine specimens for radionuclides, and only $14 \%$ reported the capability to test other clinical specimens. Expertise in clinical radiochemistry was found to be in extremely short supply. In a bit of good—or at least less badnews, the survey found that the capability to test environmental samples (60\% of respondents) and food (48\% of respondents had the ability to test nonmilk specimens, and $44 \%$ had the ability to test milk) was more widely distributed.

Were a significant radiation event to occur, it is highly likely that this limited capacity, particularly for the processing of clinical specimens, would be overwhelmed. During the first few weeks of the 2009 H1N1 influenza pandemic, for example, many public health laboratories found themselves deluged with requests to process routine clinical specimens, to the detriment of some of the laboratories' core public health functions. We should anticipate a similar demand for clinical testing after any significant radiological event.
Coordinating communication and allocating scarce clinical and laboratory resources during such an event would be a high priority. This realization galvanized CDC to align with partner organizations to establish the National Alliance for Radiation Readiness (NARR). NARR was formed in 2010 as a direct result of meetings sponsored by the CDC Radiation Studies Branch and the Conference of Radiation Control Program Directors (CRCPD). These meetings brought together, for the first time, public health organizations (the Association of State and Territorial Health Officers, the National Association of County and City Health Officials, and the Council of State and Territorial Epidemiologists [CSTE]) and radiation organizations (CRCPD). With funding from CDC, the NARR was formed with the Association of State and Territorial Health Officers, the National Association of County and City Health Officials, the Council of State and Territorial Epidemiologists, CRCPD, and the Association of Public Health Laboratories as its charter members and with a stated mission to "enhance the capabilities and capacities of local, state, and federal health officials to prepare for, respond to, and recover from radiation and nuclear public health events through effective collaboration between and among public health, emergency management, and health care partners" (personal communication from Captain D. Lynn Evans at the CDC National Center for Environmental Health). These organizations were soon joined by the American Medical Association and the National Emergency Management Association, and the list of member organizations has continued to grow. NARR has been active since its inception, most prominently in linking state and local public health and radiation agencies with their federal counterparts during the response to the Fukushima Daiichi nuclear incident in March 2011. The NARR seems well positioned not only to facilitate communication and coordination between stakeholders but to play an active role in promoting "science preparedness" for largescale emergencies. "Science preparedness" entails an ability to collect data about exposures or risks in a systematic fashion almost from the beginning of an event. Such preparedness can facilitate both near-term decision making as well as long-term management and follow-up of affected populations.

These accomplishments notwithstanding, it should not come as a surprise that the 10th anniversary of the September 11 attacks has prompted national reflection on the US government's massive investment in homeland security during the last decade. That we have reached this milestone at a moment of grave fiscal and economic uncertainty has made that reflection all the more searching. Some experts, for example, estimate that our aggregate expenditures to promote homeland security now exceed $\$ 1$ trillion. ${ }^{11}$ What have these investments delivered? What have they not delivered? What can be done to promote and maintain preparedness and homeland security in coming years, when we can anticipate that budgets will be increasingly austere?

The upsurge in homeland security spending was precipitated by specific acts of terrorism-the September 11 attacks and the 
subsequent anthrax mailings-but if the events of the last decade have demonstrated anything, it is the value of all-hazards preparedness. Who could have predicted, in 2001, that the next 10 years would include the most costly natural disaster in US history (Hurricane Katrina), an influenza pandemic, a nearpandemic in the form of the severe acute respiratory syndrome, the 2004 Sumatra-Andaman earthquake and tsunami, the 2010 Haiti earthquake, the largest offshore oil spill in US history, and the triple disaster in Japan earlier this year, which culminated in the most significant radiation release since Chernobyl, not to mention a host of less spectacular but no less real public health crises?

We need to keep this experience in mind as we assess the value of our preparedness expenditures during the last decade and contemplate new ones in the era of austerity ahead. Although the possibility of terrorists acquiring and using a weapon of mass destruction (WMD) is real but remote, the probability is high that we will experience public health emergencies in the nearto mid-term that require functioning alert-and-response systems. We often speak of WMDs as being threats of "low probability but high cost." Fair enough, but WMDs are not the only threat of concern. The threats of concern are manifold and may better be described as being of low frequency rather than low probability. Nuance is everything.

Author Affiliation: Dr Hatchett is Chief Medical Officer and Deputy Director for Strategic Sciences, Biomedical Advanced Research and Development Authority, Office of the Assistant Secretary for Preparedness and Response, Department of Health and Human Services.

Correspondence: Address correspondence and reprint requests to Dr Richard J. Hatchett, Biomedical Advanced Research and Development Authority (HHS/ ASPR/BARDA), 375 E Street, SW, Room 4411, Washington, DC 20201 (e-mail: Richard.Hatchett@hhs.gov).

Received and accepted for publication September 6, 2011.
The opinions expressed in this article are those of the author and do not necessarily reflect the views, positions or policies of the U.S. Department of Health and Human Services or its components.

Author Disclosures: The author reports no conflicts of interest.

\section{REFERENCES}

1. Dainiak N, Gent RN, Carr Z, et al. Literature review and global consensus on management of acute radiation syndrome affecting nonhematopoietic organ systems. Disaster Med Public Health Prep. 2011;5:183-201.

2. Dainiak N, Gent RN, Carr Z, et al. First global consensus for evidencebased management of the hematopoietic syndrome resulting from exposure to ionizing radiation. Disaster Med Public Health Prep. 2011;5:202212.

3. Latshaw MW, Mangal C, Barkey A, McNamara D, Kim D, Pierson JB. Public health laboratories and radiological readiness. Disaster Med Public Health Prep. 2011;5:213-217.

4. Oliveira AR, Hunt JG, Valverde NJ, Brandão-Mello CE, Farina R. Medical and related aspects of the Goiânia accident. Health Phys. 1991;60: 25-29.

5. Tuttle RM, Vaisman F, Tronko MD. Clinical presentation and clinical outcomes in Chernobyl-related paediatric thyroid cancers: what do we know now? What can we expect in the future? Clin Oncol (R Coll Radiol). 2011; 23(4):268-275.

6. Bromet EJ, Havenaar JM. Psychological and perceived health effects of the Chernobyl disaster: a 20-year review. Health Phys. 2007;93(5):516521.

7. Collins DL. Human responses to the threat of or exposure to ionizing radiation at Three Mile Island, Pennsylvania, and Goiãnia, Brazil. Mil Med. 2002;167(2)(Suppl):137-138.

8. Institute of Medicine. Assessing Medical Preparedness to Respond to a Terrorist Nuclear Event. Workshop Report. Washington, DC: National Academies Press; 2009.

9. National Security Staff Interagency Policy Coordination Subcommittee for Preparedness \& Response to Radiological and Nuclear Threats. Planning guidance for response to a nuclear detonation, 2nd ed. http://www .hps.org/hsc/documents/Planning_Guidance_for_Response_to_a_Nuclear _Detonation-2nd_Edition_FINAL.pdf. Published June 2010. Accessed September 5, 2011.

10. Guyatt GH, Oxman AD, Vist GE, et al; GRADE Working Group. GRADE: an emerging consensus on rating quality of evidence and strength of recommendations. BMJ. 2008;336(7650):924-926.

11. Mueller J, Stewart MG. Balancing the risks, benefits, and costs of homeland security. Homeland Secur Aff. 2011;7:1-26. 